\title{
Cutting Balloon Angioplasty for Intrastent Restenosis Treatment
}

\author{
João Orávio de Freitas Jr, Sérgio Luis Berti, José Geraldo Bonfá, Maria Sílvia Martins Speranza, \\ Pércio Primo Gandolphi, Hércules Lisboa Bongiovani
}

Araraquara, SP - Brazil

\begin{abstract}
We describe here two patients with angiographic diagnosis of intrastent restenosis and regional myocardial ischemia. One stent restenosis was located in a native coronary artery and the other in a vein graft. Both were treated with cutting balloon angioplasty (CBA), inflated at low pressures. Angiographic success was obtained and both patients were discharged in the day after the procedure. Cutting balloon angioplasty using low inflation pressures achieved important luminal gains, in these two cases of intrastent restenosis. Further studies are necessary before the effectiveness of this procedure can be precisely defined.
\end{abstract}

Reports of lower restenosis rates ${ }^{1,2}$, have encouraged the use of stents for treatment of coronary obstructive lesions. This technique is also used in situations not related to a lower restenosis rates where superior results are not established when compared with conventional angioplasty ${ }^{3-5}$. The consequence is an increasing incidence of intrastent restenosis where adequate treatment for long-term solutions is not well known ${ }^{7}$.

We report two cases of intrastent restenosis treated successfully with cutting balloon angioplasty, an easily performed alternative, despite the need for further studies corroborating its effectiveness.

\section{Case Report}

Case 1 - A forty-year-old hypertensive man presented with effort-limiting angina and a history of angioplasty with stent implant (angiostent $-15 \mathrm{~mm}$ ) in the left anterior descending (LAD) coronary artery one year prior. Clinical examination, as well laboratory and radiological data, were normal. Electrocardiogram (ECG) showed ischemic alterations in leads D1, AVL, V1-V6, normal right (RCA) and left circumflex (LCX) coronary arteries, as well as normal pressures and ventricular contractility. The LAD had severe $(90 \%)$ and diffuse $(15 \mathrm{~mm})$ obstructive lesion throughout the entire radiopaque stent wich was placed in its ostium (fig. 1).

Irmandade da Santa Casa de Misericórdia de Araraquara

Mailing Address: João Orávio de Freitas Jr - Santa Casa de Misericórdia - Av. José Bonifácio, 794 - 14801-150 - Araraquara, SP - Brazil
Using femoral access, we catheterized the left coronary artery with a guiding catheter Ebu 8F (Medtronic) and crossed the lesion with Mustang (Meditronic) guidewire 0.014 inches placed in the distal LAD segment. The cutting balloon (Interventional Technologies Inc., San Diego, California, USA) $3.5 / 15 \mathrm{~mm}$ was placed exactly inside the segment covered by the stent. We experienced only a slight difficulty in crossing the lesion, and only one 6 atm inflation was performed when a full balloon expansion was obtained and sustained for $2 \mathrm{~min}$ (fig. 2).

Control angiogram showed important luminal gains and an absence of visually detectable residual lesion.. There were no signs of dissection and distal flow was Timi III (fig. 3 ). The hospital course was uneventful and the patient was discharged on the day after the procedure.

Case 2 - A seventy-year-old man presented with type II diabetes mellitus but no cardiovascular symptoms. He had had coronary artery bypass surgery 13 years earlier and angioplasty with stent implant (Be Stent) in an aortoostial segment of saphenous vein graft to marginal branch (VG-Mg) three months previously. Clinical examination was normal and ECG showed diffuse alterations of ventricular repolarization. Myocardial perfusion scintigraphy (SestaMibi) revealed transient inferolateral hypokynesia of the left ventricle (LV)

Coronary angiography revealed total proximal occlusion of the LAD, LCX and RCA.. The left internal mammary artery to LAD was patent, with the native coronary artery diffusely obstructed. Vein graft to RCA was totally occluded and PS-Mg showed subocclusive lesions in the aortoostial portion, revealing intrastent restenosis (fig. 4). Left ventricular function was normal.

Angioplasty was performed through femoral access. We catheterized the VG-Mg ostium with a guiding catheter AL3 8F (Medtronic) and crossed the lesion with Stabilizer (Johnson \& Johnson) guidewire 0.014 inches, which was placed in the distal segment of the marginal branch. The cutting balloon $4.0 / 10 \mathrm{~mm}$ was placed in the obstruction site fully inside the stent (Be Stent $-15 \mathrm{~mm}$ ). Only one $5 \mathrm{~atm}$ inflation, was performed leading to full balloon expansion (fig. 5). Balloon lesion crossing was moderately difficult and 


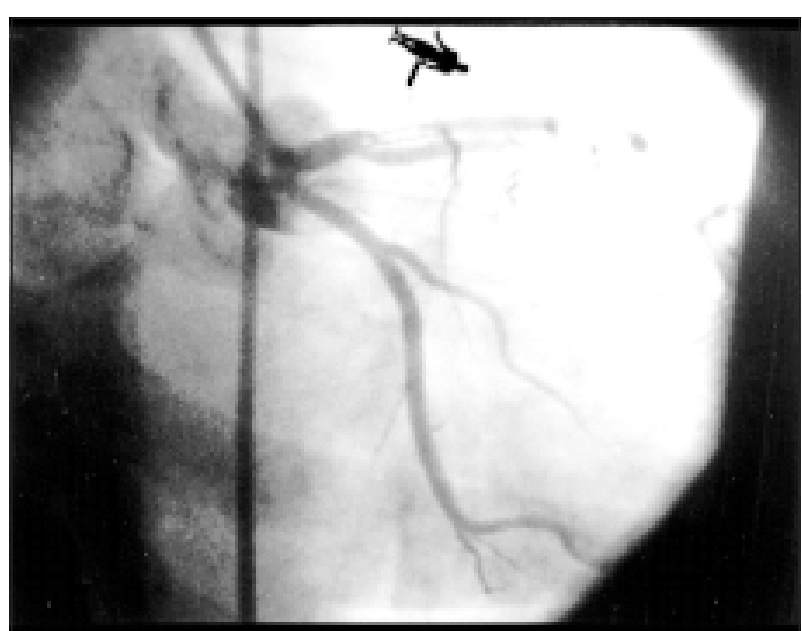

Fig. 1-Diffuse restenotic lesion.

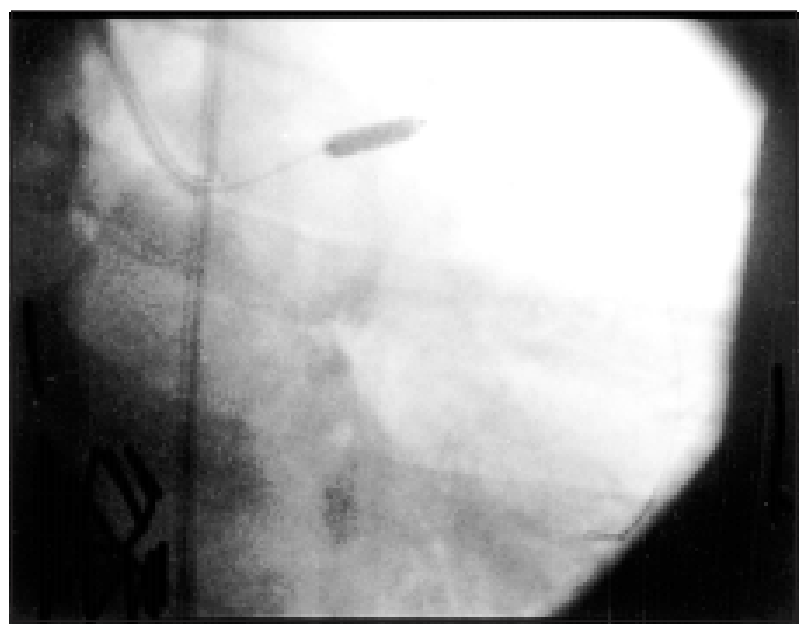

Fig. 2 - Cutting balloon $3.5 / 15 \mathrm{~mm}$ inflated inside stent.

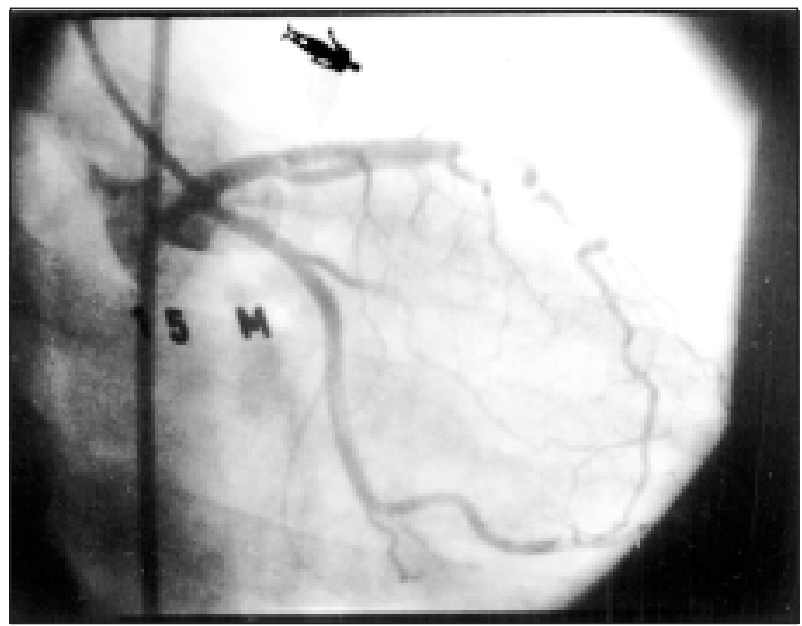

Fig. 3 - Final result.

was overcome by optimizing the guiding catheter position. Inflation was sustained for $2 \mathrm{~min}$ and control angiography revealed an important luminal gain, without residual lesions visually detectable and Timi III distal flow (fig. 6). The procedure was uneventful and the patient was discharged the following day.

\section{Discussion}

About a million angioplasties are performed yearly, worldwide. Immediate results are excellent but restenosis limits the medium-term outcome, and occurs in $30-60 \%$ of the cases ${ }^{1}$ in the first six months. With the stents, restenosis rates have reduced when implantation occurs in lesions with favorable characteristics ${ }^{2}$. However, technological advances and constant learning have expanded stent indication to lesions other than those characterized as Benestent-Stress type. Several authors have shown the superiority of using stents when compared with conventional angioplasty in cases such as saphenous vein lesions ${ }^{3}$, restenotic lesions ${ }^{4}$ and total occlusions ${ }^{5}$. However, restenosis rates greater than those observed in the Benestent and Stress studies and the treatment of this new situation has been challenging.

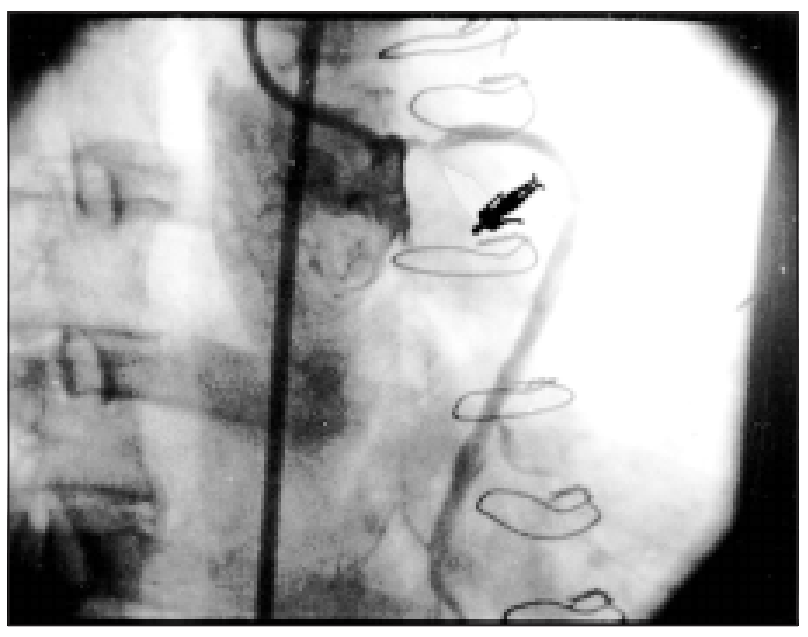

Fig. 4 - Aortoostial lesion in PS-Mg.

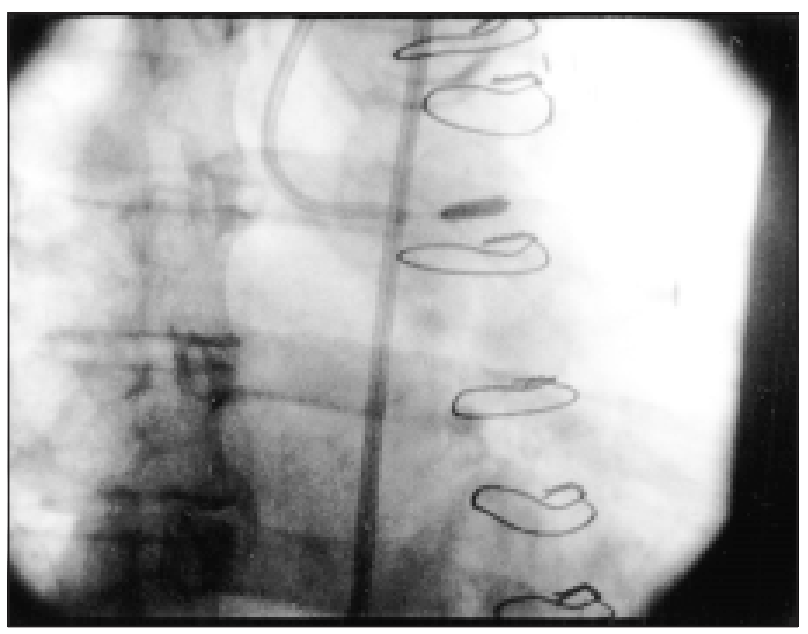

Fig. 5 -Cutting balloon 3.5/15mm inflated from PS-Mg ostium. 


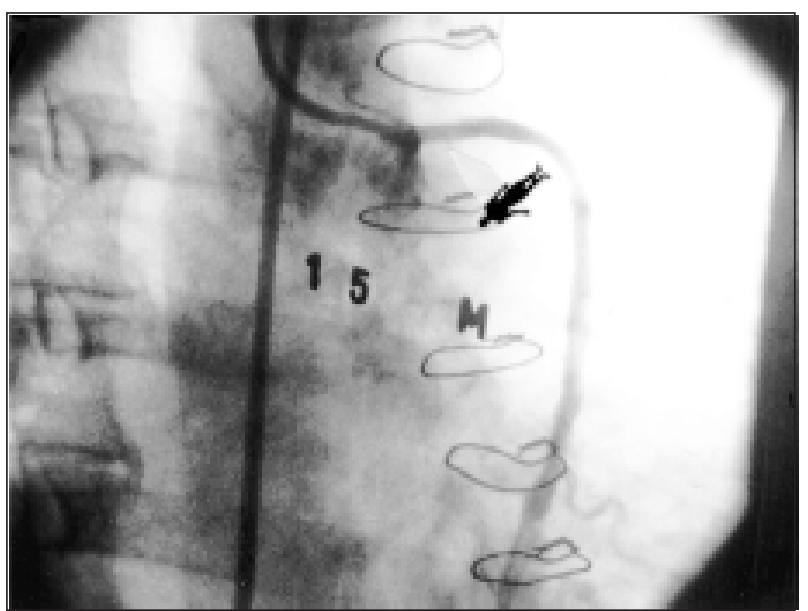

Fig. 6-Final result.

Mechanisms like stent injury in the coronary artery wall, local inflammatory reaction, radial stress, stent morphology, stent grafting as well have been implicated in the intrastent restenosis phenomenon. Predictive aspects of the occurrence of restenosis are currently identified and allow identification of high risk patients, among them, patients with multiple stents, long stents, diabetes, previous angioplasty, LAD stenting and minimal luminal diameter $<3.0 \mathrm{~mm}^{6}$.

Intrastent restenosis treatment is experimental and is prompting a few clinical randomized trials with different techniques. Conventional ballon angioplasty is not obtaining encouraging results, especially in diffuse lesions. Employment of a $2^{\text {nd }}$ stent, despite greater immediate luminal gains, does not show consistent long-term results ${ }^{7}$.

In the future, the use of ionizing radiation might offer a satisfactory answer, for treatment of intrastent restenosis. Debulking techniques, such as directional and rotational atherectomy and cutting balloon, have shown interesting initial results and several studies are being conducted aiming to show the role of such techniques. The cutting balloon, due to its common availability (technique identical to conventional angioplasty) and affordability, has attracted particular interest. This device comprises a balloon with microblades ( 3 to 4 ) radially placed that promote incision in the intimal hyperplasia layer, with the advantage of using low inflation pressures, preventing deep vessel injury.

Yamaguchi et al ${ }^{6}$ recently showed results from a Japanese study analyzing cutting balloon use for intrastent restenosis. Of 167 patients treated, $28 \%$ had restenosis in the first six months and $21 \%$ needed a new revascularization procedure.

In conclusion, we understand that, despite the need for further investigation to establish its role, the use of cutting balloon in intrastent restenosis is a safe procedure and is an easy alternative technique.

\section{Acknowledgments}

To Mrs. Renata Zilio Caetano for the helpful collaboration.

\section{References}

1. Holmes DR, Jr, Vliestra RE, Smith HC, et al. Restenosis after percutaneous transluminal coronary angioplasty (PTCA): a report from the PTCA registry of the National Heart, Lung and Blood Institute. Am J Cardiol 1984; 53(suppl): 77C-81C.

2. Serruys PW, de Jaegere P, Kiemeneij F, et al - for the Benestent Study Group. A comparision of balloon expandable stent implantation with balloon angioplasty in patients with coronary artery disease. N Engl J Med 1994; 331: 489-95.

3. Savage MP, Douglas JS, Fischman DL, et al - for the Saphenous Vein De Novo Trial Investigators. Stent placement compared with balloon angioplasty for obstructed coronary bypass grafts. N Engl J Med 1997; 337: 740-7.
4. Erbel R, Haude M, Hopp HW, et al - on behalf of the REST Study Group. Restenosis ST (REST)-Study: randomized trial comparing stenting and balloon agioplasty for treatment of restenosis after balloon angioplasty. J Am Coll Cardiol 1996; 27: 139A

5. Sirnes PA, Golf S, Myreng Y, et al. Stenting in chronic coronary occlusion (SICCO): a randomized controlled trial of adding stent implantation after successful angioplasty. J Am Coll Cardiol 1996; 28: 1444-51.

6. Belder A, Thomas M. The pathophysiology and treatment of in-stent restenosis. Stent 1998; 1: 74-82.

7. Goldberg SL, Loussararian AH, Di Mario C, et al. Stenting for in-stent restenosis. Circulation 1997; 96: I-88. 